\title{
A system for treatment of diabetic foot ulcers using led irradiation and natural latex
}

Gustavo Adolfo Marcelino de Almeida Nunes*, Maria do Carmo dos Reis, Mário Fabrício Fleury Rosa, Luciana Roberta Tenório Peixoto, Adson Ferreira da Rocha, Suélia de Siqueira Rodrigues Fleury Rosa

\begin{abstract}
Introduction: We developed and tested a new system for inducing the healing of diabetic foot ulcers. The system relies on the regenerative properties of its two components: an insole with a sheet of natural latex and a device that contains a matrix of light emitting diodes with wavelength of $635 \mathrm{~nm}$. Methods: The electronic and latex based devices were developed, and a four weeks test was performed in one control group (CG) of five ulcers and one experimental group (EG) of eight ulcers. The CG was treated with a standard approach, based on a silver-releasing foam dressing, and the EG was treated with the system under test. For each ulcer, an index for quantifying the percentage ulcer recovery, named CRU(\%), has been calculated; a CRU(\%) $=0 \%$ means no healing, and a CRU(\%) $=100 \%$ means total healing. Results: There were statistically significant increases of CRU $(\%)$ of $51.8 \%(p=0.022)$, for the CG, and of $78.4 \%(p<0.001)$, for the EG. The increase in the EG was higher than the increase in the $\mathrm{CG}$, and the difference was statistically significant $(\mathrm{p}<0.001)$. The results showed that the proposed method had, for these particular sets of ulcers, faster healing rates, than for the standard method. Conclusion: The results hint that the proposed method seems promising as a future treatment method. However, the technique must undergo further testing before it can be considered for extensive clinical applications.
\end{abstract}

Keywords: Diabetes, Tissue formation, Inducer system, Diabetic foot, Latex, LED.

\section{Introduction}

Diabetes mellitus (DM) is one of the most important public health problems nowadays, due to its high morbidity and mortality levels (Wild et al., 2004) and, in the last decades, chronic complications of DM have become the most common cause of non-traumatic amputations (Brasileiro et al., 2005; Freitas et al., 2002). DM has complications such as reduced sensitivity (neuropathy) and blood perfusion (vasculopathy). The feet are often the first part of the body to be affected by the lack of sensitivity. Patients who experience this problem lose the body's main protective mechanism, the pain, and are likely to develop foot wounds. Due to hampered blood flow, wounds usually become bigger and healing is affected. Furthermore, loss of sensitivity makes the patient vulnerable to trivial trauma, in which wounds are an entry to bacteria that cause silent and serious infections when not treated in early stages. This scenario facilitates the appearance of ulcers, which require special attention. The diabetic foot ulcer treatment depends on the degree of damage in the limb and on the presence and severity of ischemia and/or infection. Currently, there are many options for injury treatment, such as bandages with different types of coverage, devitalized tissue debridement, revascularization, hyperbaric oxygen therapy, use of cultured human dermis (Dermagraft), application of local growth factors, and amputation of extremities. Unfortunately, in many cases, the more desirable treatments fail, and the latter option end up being adopted.

This article presents a new system for the treatment of diabetic foot ulcers that conjugates two elements that are known to favor tissue regeneration: a device with a matrix of light emitting diodes (LEDs) and an insole made of natural latex. The use of these techniques in other contexts has been reported in the literature.

Phototherapy based techniques have been known for several years. In numerous studies in the literature, cells that were exposed to light showed higher growth rate than those that were not exposed. Marques et al. (2004) showed that it is possible to accomplish photobiostimulation on cells through optical fluorescence. Minatel et al. (2009) reported that phototherapy accelerated wound healing of mixed leg ulcers in two hypertensive diabetic (type 2) patients. Chaves (2011) reported that a photobiomodulation prototype made of LEDs with spectral range close to the infrared range was an effective remedy in 
the treatment of nipple trauma. Souza (2008) did a comparative study between phototherapic modalities using LEDs and LASER, and concluded that, depending on the protocol used, both kinds of radiation and their associations can yield positive biomolulation on fibroblast proliferation, granulation formation, collagen fiber deposition, and angiogenesis. Nteleki and Houreld (2012) presented a review article on the phototherapy (low-level laser therapy - LLLT), and concluded that it is a therapeutic modality that can improve wound healing.

In the last decades, several studies in the literature have reported efforts to identify substances that can promote tissue regeneration and angiogenic activity (Wang et al., 2008). Synthetic or natural materials have been used or suggested for clinical and experimental use in several species. The ideal substitute material must ideally have low cost, be easily handled, promote tissue growth, provide scar tissue similar strength to that of normal tissue, be resistant to infection, be flexible, be inert, porous, and resilient. Additionally, it should not undergo changes in physical characteristics due to contact with tissue fluids, nor cause exacerbated inflammatory response or cause adhesions or fistulas formation (Dallan, 2005; Wang et al., 2008). Natural latex is a milky liquid extracted from the Hevea brasiliensis rubber tree, which has properties that induce neovascularization, tissue regeneration and the formation of extracellular matrix (Zimmermann et al., 2007). Naturally derived, it has low cost, no risk of pathogen transmission and great clinical and social applicability (Frade et al., 2004).

Several studies in the literature have shown that natural latex has very powerful regenerative properties, which turn it into a very promising substance for use in medical applications. Mrue (2000) reported the use of a biomembrane made of natural latex mixed with the polylisine protein that effectively induced neoformation of the esofagic wall. Ferreira (2007) showed that a latex membrane can be effectively used to repair wall defects in rats that resulted from an abdominal incision, with potential applications for hernia repair. Brandao et al. (2007) reported the development of a new micro-perforated vascular graft model made of tissue and covered with a natural latex compound that showed good structural qualities as a vascular substitute, which stimulated endothelial growth and provided adequate tissue integration in dogs. Zimmermann et al. (2007) reported the development of membranes that were used to replace muscle sheath in dogs; two out of three membranes worked well as temporary implants and also induced the formation of new tissue, which led later to a definitive repair. Rodrigues (2008) developed and tested a device, in dogs, to aid obesity treatment. The system worked by controlling the flow of substances in the esophagus; the device was effective in promoting weight loss and showed perfect biocompatibility. Reis (2013) developed the system herein presented, to treat diabetic foot ulcers, which used natural latex.

The purpose of this research was to develop and test a system for inducing the regeneration of diabetic foot ulcers based on a natural latex insole and a device using light emitting diodes (LEDs).

\section{Methods}

\section{Materials}

The system developed is composed of an insole made of natural latex and a device with a matrix of red LEDs. The insole was custom made for each subject, and its main purpose is to provide continuous mechanical support to the healing latex sheet while keeping the patient comfortable enough. To fabricate it, we used a mixture of alginate and water to make a mold with the shape of the outer contour of the foot, and we used this mold to make another one, made of plaster, with the shape of the patient's foot. Afterwards, the mold was submitted to successive slow immersions in a latex compound, followed by heating in a thermostatic oven. Finally, a gap was made at the insole, at the position of the ulcerated area. During the application of the experimental treatment, a specially fabricated latex sheet would fill that hole, so that only this sheet will be in contact with the ulcer (Figure 1a).

The latex sheet has been made with centrifuged $60 \%$ latex biomaterial. In the manufacturing process, the latex was placed in a glass or an acrylic Petri dish, previously cleaned and dried, where the latex biomaterial was spread to form a thin layer, covering the dish surface. The Petri dish was not left horizontally in the oven - it was fully rested in a vertical position so that any latex excess would be drained. This procedure led to a more transparent sheet. We repeated the process 6 times, and the resulting final sheet thickness was $0.5 \mathrm{~mm}$. The latex sheets were cut generally in rectangular shapes and then sterilized with ethylene oxide. We made sheets with different sizes in order to match different ulcer sizes. Purposely, we made the slides slightly larger than the extent of the wound, to ensure the total covering of the ulcerated area. The latex sheets were tested at the Optical Spectroscopy Laboratory of the Institute of Physics at the University of Brasilia, in order to verify if it does not cause excessive attenuation or significant changes in the spectral characteristics of the light irradiated by the LED matrix. The results showed 

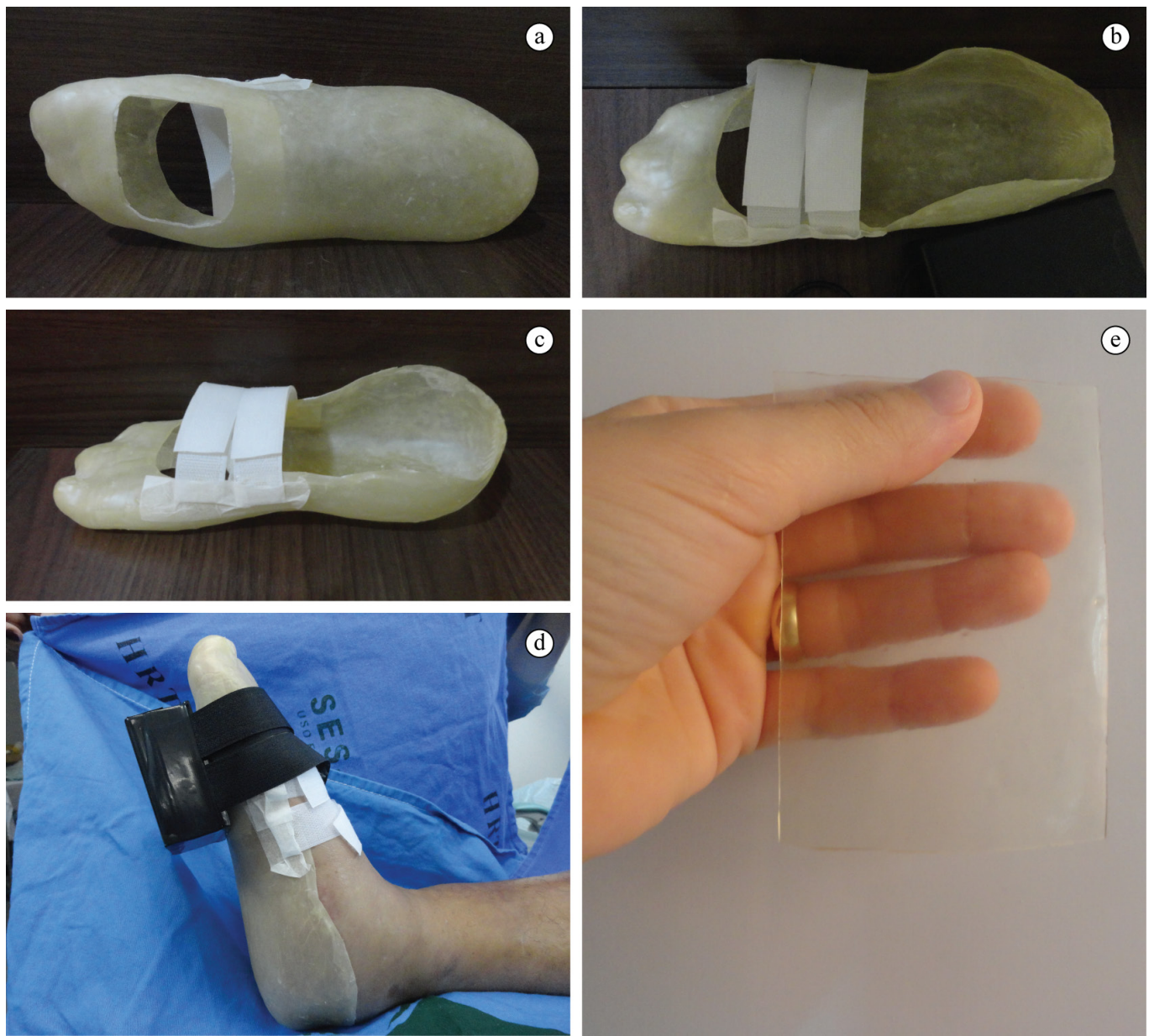

(d) A patient using the insole, with the light-emitting device strapped

Figure 1. Healing insole: (a) Bottom view; (b) Top view; (c) side view;
to the foot, at the position of the ulcer; (e) Example of a latex sheet.

that the sheet causes a reduction of approximately a half in the intensity of the light, but had no effect in its spectrum. Different views of the insole are shown in Figure 1: (a) bottom view; (b) top view, (c) side view. In (d), the foot of a patient using the insole, with the light-emitting device strapped to the foot, at the position of the ulcer, is shown. In (e), an example of a latex sheet is presented.

The second part of the system is the light emitting unit, which contained a matrix of LEDs that contains 31 high intensity red LEDs with $5 \mathrm{~mm}$ diameter, with peak wavelength between 635 and $640 \mathrm{~nm}$. Each LED was supplied with a $3 \mathrm{~mA}$ current. The matrix had four rows with four LEDs, intercalated with three rows with five LEDs. The distance between the LEDs was $10 \mathrm{~mm}$ and the distance between the columns was $7 \mathrm{~mm}$. The circuit contained a battery with autonomy for several hours, a built-in timing system and a sound alarm. A separate power source has been built to allow the recharging of the system's battery. The matrix and its controlling and power supply circuits were fixed in an acrylic box with a transparent top. The physical features of the circuit are presented in Figure 2. Figure 2a shows the insole and the matrix side by side. Figure $2 \mathrm{~b}$ shows the two units with the matrix on, close to the charging power source. Figure $2 \mathrm{c}$ shows constructive details of the matrix. Figure $2 \mathrm{~d}$ is a version of Figure $2 \mathrm{c}$ with the lights on. Figure 2e shows the spectrum of the LED light that goes in (red curve) and out (blue curve) of the latex sheet. In all tested LEDs, the peak intensities were between the wavelengths of 635 and $640 \mathrm{~nm}$, as specified by the manufacturers, and the attenuation was always of about half the intensity. There was no significant change in the relative spectral content. Figure $2 \mathrm{f}$ shows a partial view of the internal circuits.

\section{Subjects}

We conducted a study to test the efficiency of the system developed in healing chronic ulcers associated with diabetic foot. The tests included 5 patients that had 10 diabetic foot ulcers. The study protocol has 

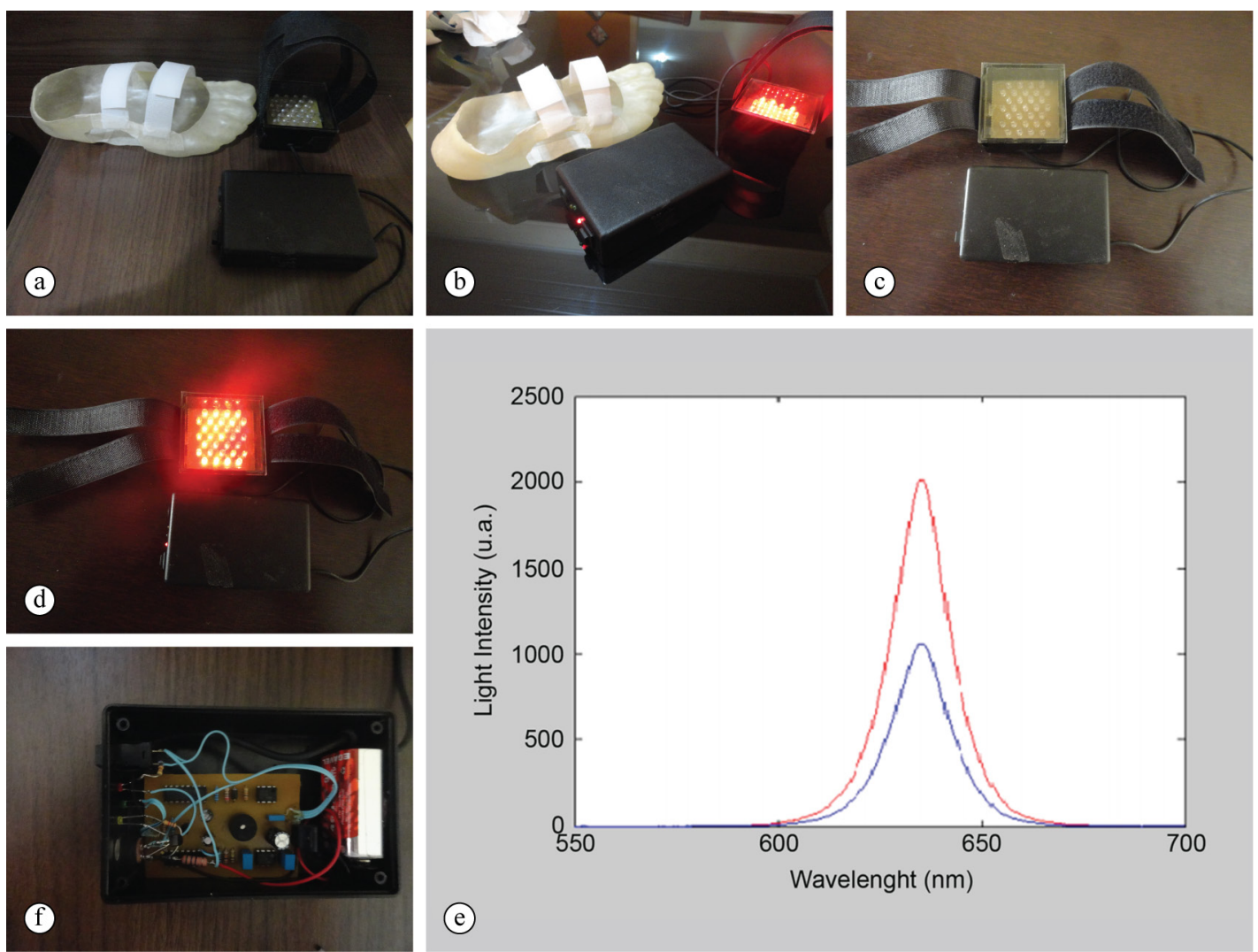

(f)

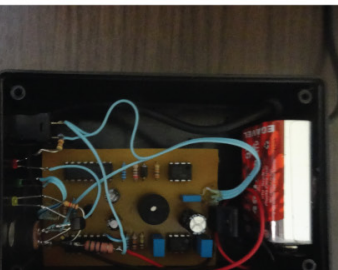

Figur

Figure 2. The physical implementation of the light-emitting circuit. (a) The insole and the matrix side by side; (b) The insole, the battery charging power supply and the LED matrix, with the LEDs on; (c) Constructive details of the circuit; (d) Same as figure d, but with the lights on; (e) The spectrum of the LED light that goes in (red curve) and out (blue curve) of the sheet; (f) View of the internal circuits. In all tested LEDs, the peak intensities were between the wavelengths of 635 and $640 \mathrm{~nm}$, as specified by the manufacturers, and the attenuation was always of about half the intensity. There was no significant change in the relative spectral content.

been approved by a local Ethics Committee (protocol: protocol 052/2012 - CEP/SES/DF), and conducted according to the directives of the Helsinki Declaration of 2008. Each patient received detailed explanations about the procedure and signed a written informed consent.

The tests were performed at the Taguatinga Regional Hospital, in Taguatinga (Federal District, Brazil), which has a team specialized in the treatment of diabetic foot ulcers.

\section{Experimental Protocol}

The hospital's clinical staff selected five patients using judgmental sampling. The patients were interviewed using a questionnaire on diabetes control and etiology of diabetic foot (ulcers with neuropathic or vascular origin), type of diabetes (type 1 or type 2), time since diabetes diagnosis, peripheral neuropathy symptoms, feet aspect, previous history of ulcers, number and aspect of the lesions. In addition, personal data were collected, such as identification, age, weight, height, gender, occupation, associated diseases, and drugs in use. There was also an evaluation of aspects related to diabetes, foot inspection, the degree of diabetic foot lesions according to the University of Texas classification.

After the evaluation, the clinical staff and the research team assigned, using convenience-based criteria, each ulcer either to the control group (CG) or to the experimental group (which was named EG1). In some patients that had more than one ulcer, different ulcers could be assigned to different groups.

In the control group, the ulcers were treated with the conventional approach for a minimum of 28 days and were weekly monitored by the hospital's staff. Before applying the bandage with silver-releasing foam dressing, a nurse performed the wound debridement of devitalized tissue and cleaning, with $0.9 \%$ physiological saline and gauze. After cleaning, the ulcer was dried with gauze and was prepared to receive the healing bandage. The dressing exchange was performed every 5 days, at home, by the patients or by their families, except on days of clinical evaluation, when an ambulatory nurse changed the bandage. Even when 
the dressing exchange was performed at home, it was necessary that the patient cleaned the wound with $0.9 \%$ physiological saline and gauze. The foam dressing is an antibacterial bandage impregnated with silver ions, which are released continuously, as the secretion is absorbed. The silver-releasing foam dressing provides a humid environment, which is an important healing factor (Brem et al., 2004).

The ulcers in the experimental group were also treated for 28 days. The ulcers received treatment with the tissue regeneration system and were monitored weekly by the hospital staff. The tissue regeneration system can be used either in a hospital environment or in daily use. In this trial, most of the treatment was done at the patient's home. After the clinical evaluation and the assignment of the patient for the experimental group, the foot mold was prepared and the custom made insole was prepared for use in another day. When the patient returned, he received detailed instructions on how to use the system at home.

In the test period, at home, before using the system, the patient had to clean the ulcer with $0.9 \%$ physiological saline and gauze. After the cleaning process, the patient rested on his sofa or bed, picked the latex sheet up, sterilized and sealed in its own package, and placed it in the gap that was built in the insole, in such a way that the latex sheet would cover the entire extent of the wound, including its edges. Then, the patient would wear the insole, securing it with Velcro strips. The next step was to strap the LED matrix to the insole, right outside the wounded area, so that the light could reach the latex sheet and the ulcer. In addition, the patient would put a piece of plastic wrap (PVC) on the LED light-radiating cell to prevent contamination. At this moment, the patient turned the device on to initiate the irradiation of the ulcer with light from the LED matrix. During the procedure, the patient had to rest on a sofa or bed, without walking. After 35 minutes, the system would sound an alarm, and the patient should turn the circuit off and remove the light-emitting device. After the removal of the LED matrix, gauze was placed on top of the wound region, and a bandage was used to hold the gauze. The gauze and bandage absorbed the eliminated wound secretion, since the latex sheet had small holes for that purpose. It was recommended that the patient remained with the healing insole all day long or for a period of at least 10 hours. However, the latex sheet should remain in contact with the wound 24 hours a day. Once a day, the patient should repeat all wound cleaning procedure, changing the latex sheet and using the tissue regeneration electronic circuit. It is noteworthy that the latex sheet was disposable and should be changed every day, and that the insole should be changed weekly or every 10 days. Three times a week, the patient should charge the tissue regeneration electronic circuit for a period of 8 hours.

\section{Evaluation of ulcer healing by image analysis}

All $\mathrm{p}$ atients included in the study were evaluated weekly. The evaluations were conducted by the medical staff and by the research team, using a photographic documentation protocol. The ulcers were photographed weekly using a digital camera, Sony DSC-H70, with a resolution of 16.1 megapixels. The images were standardized by positioning patients on a chair, with the camera assembled on a tripod parallel to the wounds, with a focal distance length of $15 \mathrm{~cm}$. A millimeter ruler was placed at the wound margin for further computational analysis. The digital images obtained were analyzed using the Image ${ }^{\circledR}$ software, which is an open source, public domain software. This software has tools that allow one to delimitate the ulcer area, and provide an estimate for the area. These estimates allowed us to estimate the decrease of the ulcers with time and, from that, to quantify ulcer healing.

After the quantification of the total ulcer area, we calculated indexes that are used in the literature for assessing re-epithelialization (Al-Watban and Andres, 2003; Robson et al., 2001, Yu et al., 1997). In this article, we used the following index:

$$
\operatorname{CRU}(\%)=\frac{\left(\mathrm{A}_{\mathrm{i}}-\mathrm{A}_{\mathrm{f}}\right)}{\mathrm{A}_{\mathrm{i}}} \times 100,
$$

where $\mathrm{CRU}(\%)$ is the index for percentage contraction of the ulcer, $\mathrm{A}_{\mathrm{i}}$ is the initial area or the ulcer and $\mathrm{A}_{\mathrm{f}}$ is the final area. A value of IUH $=100 \%$ indicates total re-epithelialization (total healing), and a value of $\mathrm{IUH}=0 \%$ indicates no signs of re-epithelialization. IUH $>0 \%$ indicates ulcers area reduction and IUH $<0 \%$, ulcer area increase. This index was used to evaluate the performance of the proposed system and to compare its performance with the performance of the standard procedure.

\section{Results}

All selected patients had type 2 diabetes, and some had more than one ulcer. A summary of the group assignments is shown in Table 1. Patients 2 and 4 had one ulcer, patient 1 and 5 had two ulcers and patient 3 had 4 ulcers. The ulcers were very different in type, location and degree; more details on the patients' characteristics can be found in the work published by Reis (2013).

Patient 1 had one ulcer assigned to the CG, and another, to the EG1; Patient 2 had one ulcer assigned 
to the EG1; Patient 3 had one ulcer assigned to the CG and three assigned to the EG1; Patient 4 had one ulcer assigned to the CG; and Patient 5 had two ulcers assigned to the CG. Patients 4 and 5 agreed to participate in the experiment in two stages: they volunteered to participate 4 weeks in the $C G$, and after, that, since their ulcers were only partially healed, they volunteered for 4 more weeks as experimental group volunteers (EG2). Thus, there were five ulcers in the $\mathrm{CG}$, five in the EG1 and three in the EG2. Therefore, there were a total of 8 ulcers in the experimental group $(\mathrm{EG}=\mathrm{EG} 1+\mathrm{EG} 2)$.

The experiments for the $\mathrm{CG}$ and the EG were performed as described in the Methods section, and the CRUs(\%) were calculated and tabulated at the beginning of the experiment and at the end of the second and fourth weeks. The areas measured for the five ulcers of the CG, in the initial week (week 0) and in the end of weeks 2 and 4, are presented in Table 2. These area values were used to calculate the correspondent $\mathrm{CRU}(\%)$, which were also included in Table 2.
The same process was done for the areas and CRUs(\%) of the EG ulcers, and these data were tabulated in Table 3.

The results presented in Table 2, for the CRUs( $\%)$ of the CG, are presented, in graphical form, in Figure 3,

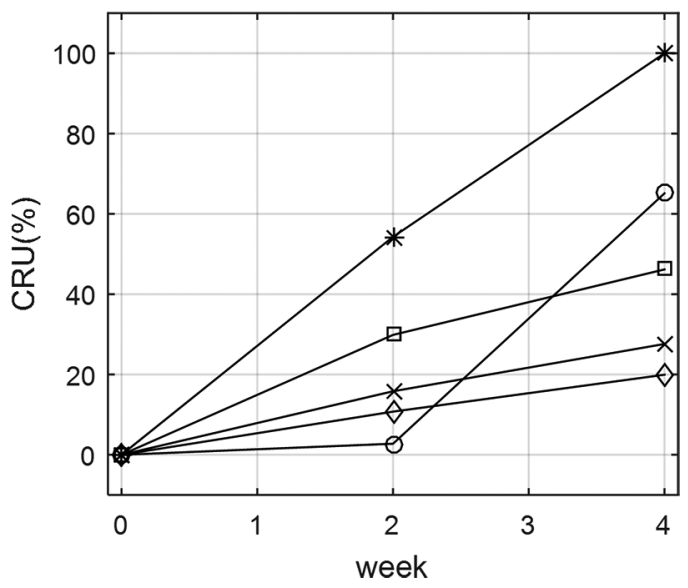

Figure 3. Graphical representation of the CRUs(\%) measured for the five ulcers of the $\mathrm{CG}$, in the initial week and at the end of weeks 2 and 4 .

Table 1. Patient data.

\begin{tabular}{|c|c|c|c|c|c|c|c|}
\hline Patient & CG & EG 1 & EG 2 & TNU & Age & Sex & TSDDM \\
\hline 1 & 1 & 1 & 0 & 2 & 46 & $\mathrm{~F}$ & 17 \\
\hline 2 & 0 & 1 & 0 & 1 & 53 & $\mathrm{M}$ & 12 \\
\hline 3 & 1 & 3 & 0 & 4 & 57 & $\mathrm{~F}$ & 24 \\
\hline 4 & 1 & 0 & 1 & 1 & 68 & $\mathrm{M}$ & 29 \\
\hline 5 & 2 & 0 & 2 & 2 & 62 & $\mathrm{~F}$ & 8 \\
\hline
\end{tabular}

CG: Number of ulcers assigned to the control group. EG1: Number of ulcers assigned to the experimental group in the first four weeks. EG2: Number of ulcers assigned to the experimental group after having a partial treatment of four weeks in the control group. TNU: Total number of ulcers. TSDDM: Time since the diagnosis of diabetes mellitus.

Table 2. The areas measured for the five ulcers of the CG, in the initial week and at end of weeks 2 and 4 , and the correspondent values of CRU (\%).

\begin{tabular}{cccccccc}
\hline Patient & Ulcer & $\begin{array}{c}\text { Area } \\
\text { Week 0 }\end{array}$ & $\begin{array}{c}\text { Area } \\
\text { Week 2 }\end{array}$ & $\begin{array}{c}\text { Area } \\
\text { Week 4 }\end{array}$ & $\begin{array}{c}\text { CRU (\%) } \\
\text { Week 0 }\end{array}$ & $\begin{array}{c}\text { CRU (\%) } \\
\text { Week 2 }\end{array}$ & $\begin{array}{c}\text { CRU (\%) } \\
\text { Week 4 }\end{array}$ \\
\hline 1 & I & 1.015 & 0.987 & 0.354 & 0 & 2.759 \\
3 & I & 0.350 & 0.160 & 0.000 & 0 & 54.286 & 29.123 \\
4 & I & 8.412 & 5.900 & 4.528 & 0 & 11.115 \\
5 & I & 26.88 & 23.99 & 21.52 & 0 & 20.267 \\
5 & II & 5.981 & 5.035 & 4.330 & 0 & 27.604 \\
\hline
\end{tabular}

Table 3. The areas measured for the eight ulcers of the EG, in the initial week and at end of weeks 2 and 4 , and the correspondent values of CRU(\%).

\begin{tabular}{|c|c|c|c|c|c|c|c|}
\hline Patient & Ulcer & $\begin{array}{c}\text { Area } \\
\text { Week } 0\end{array}$ & $\begin{array}{c}\text { Area } \\
\text { Week } 2\end{array}$ & $\begin{array}{c}\text { Area } \\
\text { Week } 4\end{array}$ & $\begin{array}{c}\text { CRU (\%) } \\
\text { Week } 0\end{array}$ & $\begin{array}{c}\text { CRU (\%) } \\
\text { Week } 2\end{array}$ & $\begin{array}{c}\text { CRU (\%) } \\
\text { Week } 4\end{array}$ \\
\hline 1 & II & 1.047 & 0.435 & 0.140 & 0 & 58.452 & 86.628 \\
\hline 2 & I & 2.652 & 0 & 0 & 0 & 100 & 100 \\
\hline 3 & II & 10.580 & 5.932 & 1.065 & 0 & 43.931 & 89.933 \\
\hline 3 & III & 0.810 & 0.225 & 0.099 & 0 & 72.222 & 87.777 \\
\hline 3 & IV & 1.410 & 0.349 & 0.283 & 0 & 75.248 & 79.929 \\
\hline 4 & I & 4.528 & 2.340 & 1.317 & 0 & 48.321 & 70.914 \\
\hline 5 & I & 21.52 & 17.17 & 11.29 & 0 & 20.213 & 47.537 \\
\hline 5 & II & 4.330 & 2.847 & 1.547 & 0 & 34.249 & 64.272 \\
\hline
\end{tabular}


and the results presented in Table 3, for the CRUs(\%) of the EG, are presented in Figure 4.

Figure 5 shows the averaged values of the curves shown in Figures 3 and 4, to facilitate a comparison. The full line curve shows the average curve for the $\mathrm{CG}$, and the dashed line, for the CE. For the CG, the CRU (\%) had, in week 2, an average increase from $0 \%$ to $22.7 \%$. To test if this increase was statistically significant, we used the Lilliefors test to check if a parametric test can be used; if the test indicated that the data was not normal, we would use the Wilcoxon test. Since the test indicated, in this case, a normal distribution, we used a Student's t-test, which yielded a p-value of 0.066. For week 4, the CRU (\%) was $78.4 \%$, and the t-test (after the Lilliefors test) resulted in $\mathrm{p}=0.022$.

For the EG, a visual inspection of Figure 5 shows that there were increases in the $\mathrm{CRU}(\%)$, from the

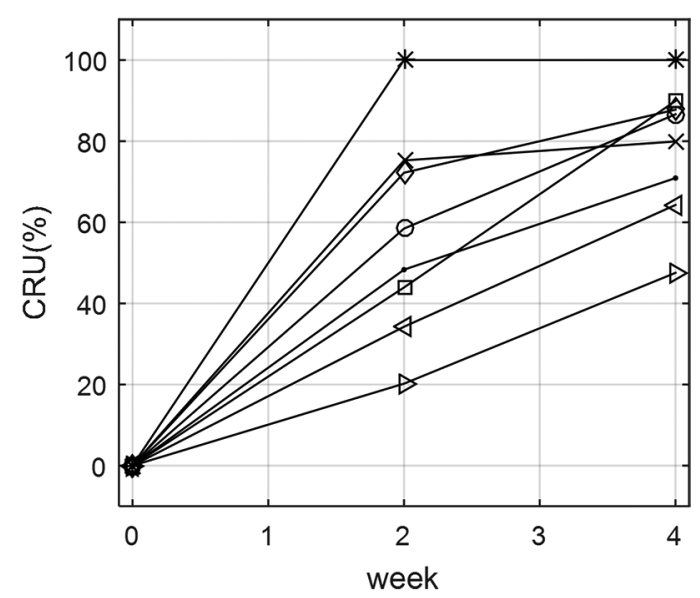

Figure 4. Graphical representation he CRUs(\%) measured for the five ulcers of the EG, in the initial week and at the end of weeks 2 and 4 .

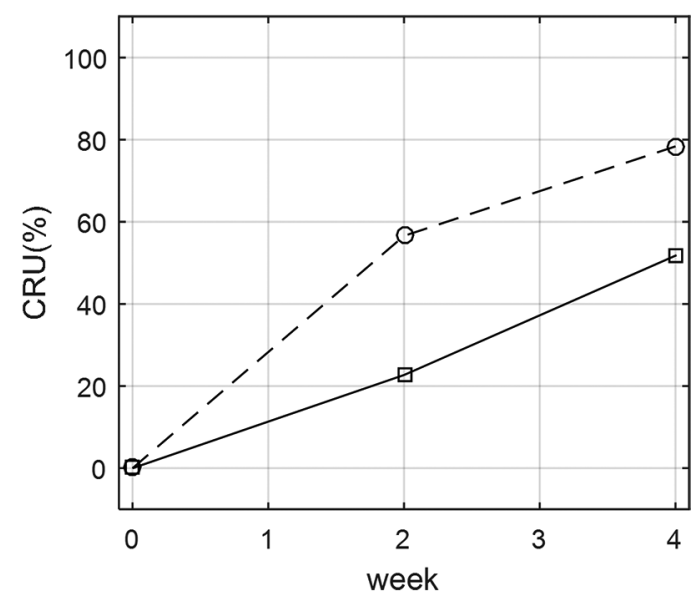

Figure 5. Averaged values of the curves shown in Figures 3 and 4. Solid line: average increase curve for the CG. Dashed line: average increase for the EG. initial value of $0 \%$, to $51.8 \%$ in week 2 and to $78.4 \%$ in week 4. By examining Table 3 , one can see that this increase happened to all the eight subjects. To test if these increases are statistically significant, the t-tests were performed (after the Lilliefors test), and the results were $\mathrm{p}<0.001$ for week 2 , and $\mathrm{p}<0.001$ for week 4 .

Student's t-test for samples of different sizes has been used to determine if there is a statistically significant difference in the performances of the two methods, for the results in week 4 , and the obtained $\mathrm{p}$-value was $\mathrm{p}<0.001$; this means that the higher CRU (\%) for the EG was statically significant.

After the study, the hospital's clinical staff continued the treatment further until the complete healing or significant improvement of the ulcers in all five volunteers. All the processes were photographically documented with weekly taken pictures.

To illustrate the healing process in two cases, Figure 6 illustrates the healing process of patient 3 (second ulcer), and Figure 7 illustrates the healing process of patient 4 , when he participated in the experimental group. The patients had good but partial healing processes during the 4 weeks of the experiment, but continued to use the experimental treatment until their ulcers had significant improvement.

\section{Discussion}

An initial visual inspection of the results presented in Table 2 and Figures 3 and 5, which estimate the effectiveness of the standard treatment with silver-releasing foam dressing in reducing the diabetic foot ulcers, suggest that the treatment was effective in reducing the ulcers. It is important to mention that the patients that were treated did not have ulcers that would heal spontaneously. On the contrary, their ulcer sizes had increasing trends when they looked for specialized help, due to the diabetes mellitus. Thus, convincing evidence that the ulcers decrease, or that the ulcer healing increase, can be considered a good result. The results presented in Table 2 and in Figures 3 and 5, along with the value of $p=0.022$, in week four, show that there was an increase in the amount of regeneration in the ulcer, and that this increase was statistically significant. The effectiveness of the treatment was further corroborated by the fact that some of the ulcers were completely healed during the 4 weeks period, and some were completely healed after the end of this period, as the patient continued the treatment. This result was expected, since the effectiveness of the standard treatment has been well documented in the literature (Jorgensen et al., 2005).

Visual inspection of Table 3, and Figures 4 and 5, also suggest the effectiveness of the experimental 

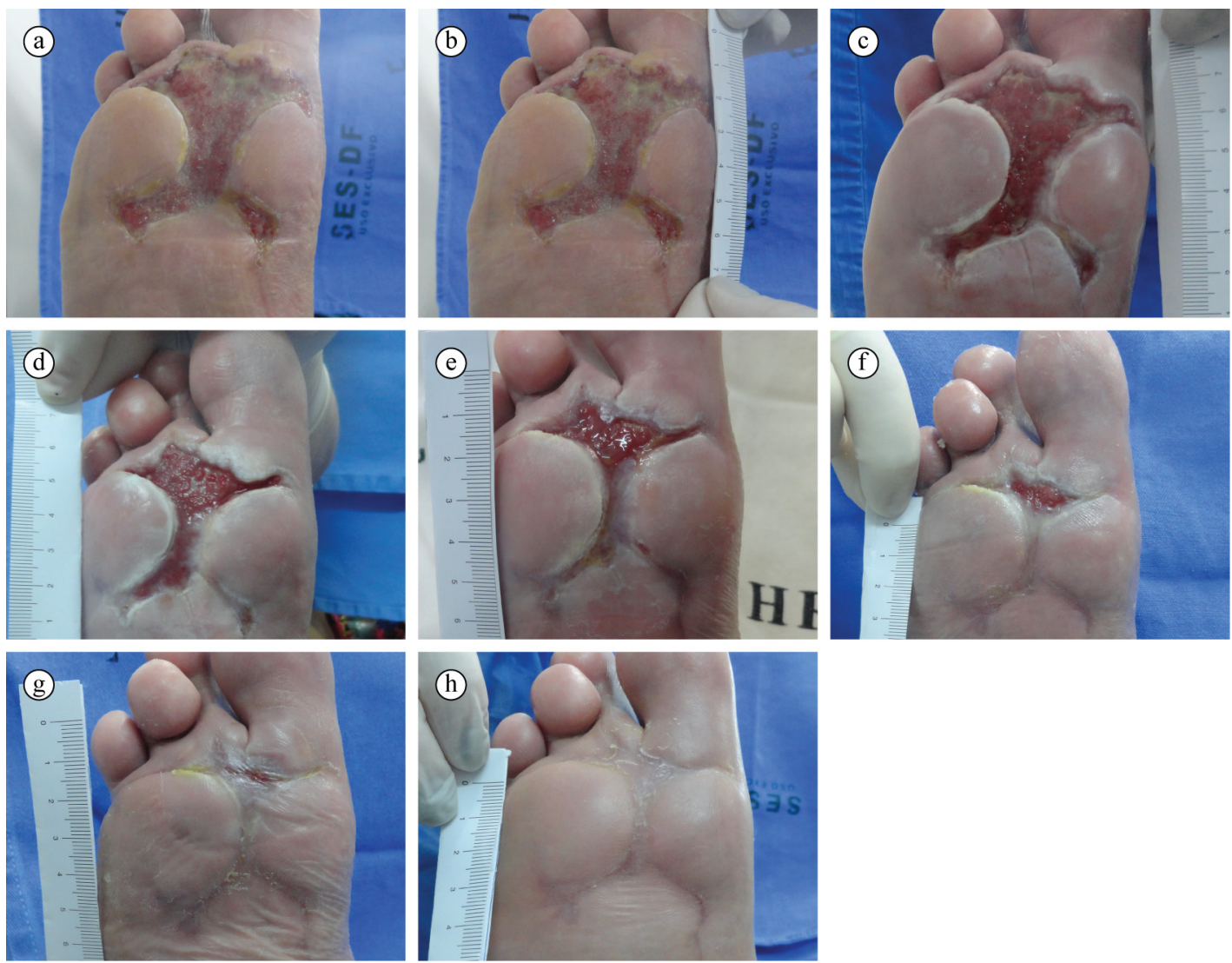

Figure 6. Photographic registration of the healing process. Patient 3, ulcer II, experimental group. (a) Location of the ulcer in the foot; (b) Before treatment; (c) 1 week after the beginning of the treatment; (d) 2 weeks; (e) 3 weeks; (f) 4 weeks; (g) 5 weeks; (h) 6 weeks.

method. After two weeks, every ulcer showed increased CRU (\%), and the same was true for the next two weeks. At week 2, the CRUs (\%) reached an average increase of $57.8 \%$ and, at week 4 , the average increase was $78,4 \%$. The p-values in both cases were $p<0.001$, showing that there is very high statistical significance for week 2 and week 4 . This is strong evidence that this method has good potential to become a clinically viable method in the future. Another compelling evidence was that all patients that continued the treatment for a few more weeks had their ulcers either completely or almost completely healed.

Both the standard and the experimental methods had positive results: in week four, the standard method led to an average $\mathrm{CRU}(\%)$ of $51.8 \%$, and the experimental method, to an average CRU (\%) of 78.4\%. To know if this difference was statistically significant, the results of the control and the experimental methods were compared using student's t-test for samples with different sizes. The obtained $\mathrm{p}$-value was $\mathrm{p}<0.001$, which shows that the difference was statistically significant, indicating that the experimental method led to a higher healing rate than the standard one.
However, this result should be viewed with extreme caution, since the methodology used had many limitations. Due to practical reasons, the patients had to be recruited using judgmental sampling, and the ulcers had to be assigned according to convenience issues. Some examples of the difficulties encountered were: (i) the number of patients that were good fits for the experiments, given its complexity and the logistic difficulties of the experiment, was small; (ii) not every patient would agree to use either method, or to use both. Thus, even though the results hint that the method have very good potential to become an effective option, in the near future, for the treatment of diabetic foot ulcers, the limitations of the methodology used should be taken into account when the results are to be analyzed and/or used.

During the tests, no noticeable clinical side effects were observed. In some cases, there were reports that in some periods the insole would generate moderate odor. This odor was a result of the natural odor of rubber (latex), added to the foot's own odor. To solve this problem it has been recommended that patients reduced the time spent with the insole and, instead of using it 24 hours a day, reduce the use to about 

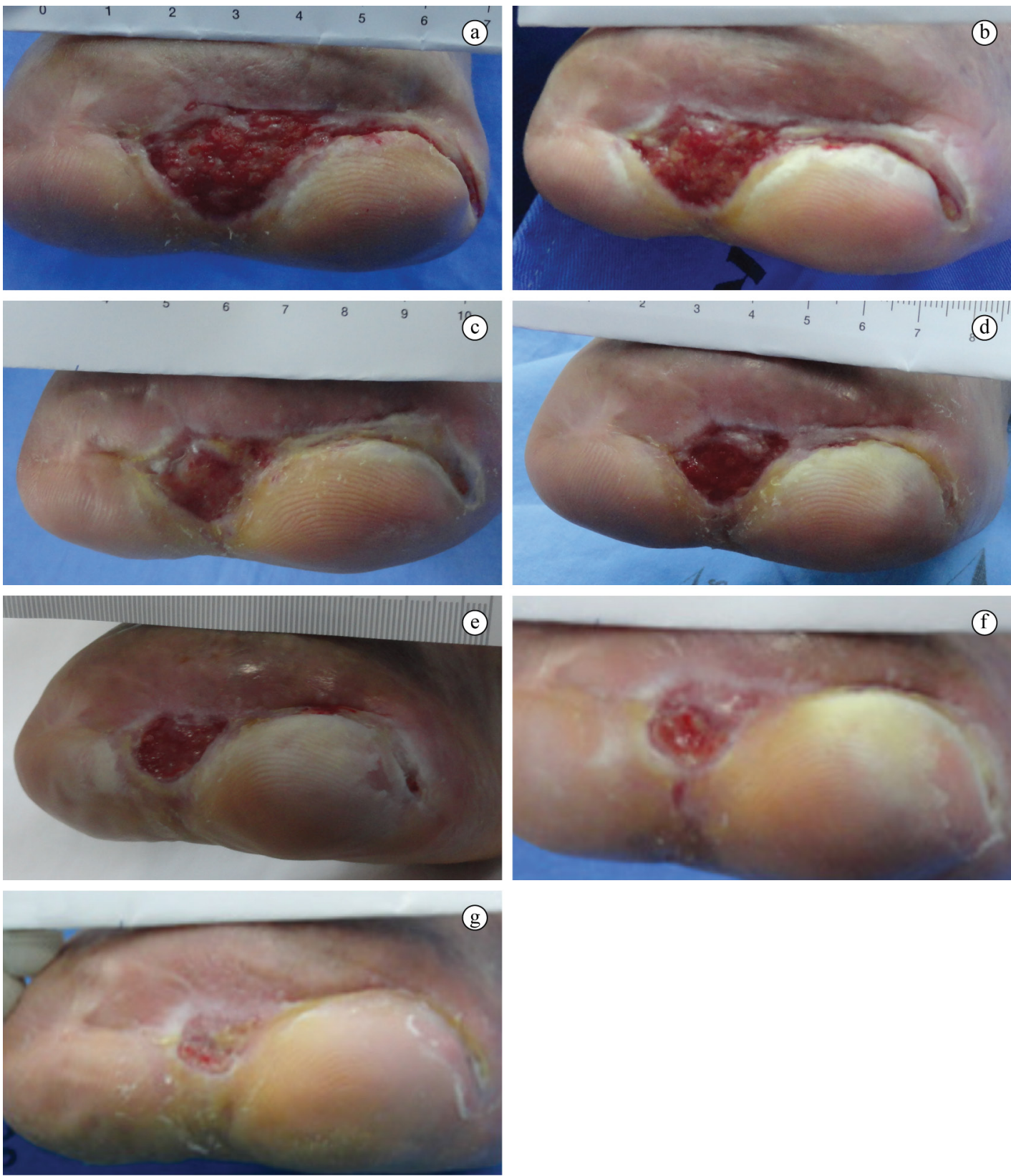

Figure 7. Photographic registration of the healing process. Patient 4, ulcer I, experimental group. (a) Untreated ulcer; (b) 1 week after the beginning of the treatment; (c) 2 weeks; (d) 3 weeks; (e) 4 weeks; (f) 6 weeks; (g) 8 weeks.

8 or 10 hours, or use it on alternate days. This fact did not affect the healing process, since the healing agents are the latex sheet and the LED light, and, when the patients were not wearing the insole, they continued to use with the latex sheet 24 hours on a daily base. After the patient removed the insole, gauze and bandage were used to fix the latex sheet into the wound. Patients reported this odor problem after two weeks of treatment. This approach solved the problem, when it appeared, in a satisfactory way.
The results herein presented are in agreement with reports, in the literature, that phototherapy using LEDs with wavelengths between 600 and $1000 \mathrm{~nm}$ promote tissue repair. This fact is in line with other works in the literature (Caetano, 2008; Erdle et al., 2008; Minatel et al., 2009; Siqueira et al., 2009) that also demonstrated that phototherapy with LEDs accelerates wound healing. The results are also consistent with the latex-related literature (Frade et al., 2004; Mrue, 2000), which have shown that the natural latex blade enhances the induction of wound healing. 
All patients that used the experimental system were satisfied with the results and reported that the latex blade insole, and the radiating LED light cell were easy and simple to use.

This study has a limitation: since the system used two conjugated methods (the natural latex and the LED light) the experiment did not allow us to find out in which extent each method contributed to the healing process. Since there are no studies on the use of these methods in the healing of diabetic foot ulcers in the literature, new experiments are needed in order to answer this question. Possibly, preliminary experiments with animal models would be desirable, since they would allow testing with more homogeneous ulcers, and with higher number of cases.

In conclusion, the results herein presented hinted that the proposed system has good potential to become a good option of the treatment of diabetic foot ulcers in the near future, but it still needs to undergo further development.

\section{Acknowledgements}

The authors are grateful to Dr. Hermelinda Cordeiro Pedrosa and to the clinical staff of the Diabetic Foot Center of the Regional Hospital of Taguatinga. We are also grateful to CNPq and CAPES for their financial support.

\section{References}

Al-Watban FAH, Andres BL. Polychromatic LED therapy in burn healing of non-diabetic and diabetic rats. Journal of Clinical Laser Medicine \& Surgery. 2003; 21(5):249-58. http:// dx.doi.org/10.1089/104454703322564451. PMid:14651792.

Brandao ML, Coutinho JC No, Thomazini JA, Lachat JJ, Muglia VF, Piccinato CE. Prótese vascular derivada do látex. Jornal Vascular Brasileiro. 2007; 6(2):130-41. http:// dx.doi.org/10.1590/S1677-54492007000200007.

Brasileiro JL, Oliveira WTP, Monteiro LB, Chen J, Pinho EL Jr, Molkenthin S, Santos MA. Pé diabético: aspectos clínicos. Jornal Vascular Brasileiro. 2005; 4(1):11-21.

Brem H, Sheehan P, Boulton AJM. Protocol for treatment of diabetic foot ulcers. American Journal of Surgery. 2004; 187(5):1-10. http://dx.doi.org/10.1016/S0002-9610(03)00299-X. PMid:15147985.

Caetano KS. Avaliação do tratamento de ulceras venosas crônicas com fototerapia (LEDs) e sulfadiazina de prata a 1\% [dissertation]. São Carlos: Universidade de São Paulo; 2008. 100 p.

Chaves MEA. Validação de um protótipo fotobiomodulador para tratamento de traumas mamilares [dissertation]. Belo Horizonte: Universidade Federal de Minas Gerais; 2011. 62 p.
Dallan PRM. Síntese e caracterização de membranas de quitosana para aplicação na regeneração de pele [thesis]. Campinas: Universidade Estadual de Campinas; 2005. 212 p.

Erdle BJ, Brouxhon S, Kaplan M, Vanbuskirk J, Pentland AP. Effects of continuous-wave $(670-\mathrm{nm})$ red light on wound healing. Dermatologic Surgery. 2008; 34(3):3205. http://dx.doi.org/10.1111/j.1524-4725.2007.34065.x. PMid:18177400.

Ferreira PG. Avaliação do efeito da membrana de látex de Hevea Brasiliensis no reparo de defeito da parede abdominal de rato [dissertation]. Alfenas: Universidade Federal de Alfenas; 2007. 50 p.

Frade MAC, Cursi IB, Andrade FF, Coutinho-Netto J, Barbetta FM, Foss NT. Management of diabetic skin wounds with a natural latex biomembrane. Medicina Cutanea IberoLatino-Americana. 2004; 32(4):157-62.

Freitas AM, Correa ZMS, Marcon IM, Schmidt H. A proteinúria como fator de risco para retinopatia diabética. Arquivos Brasileiros de Oftalmologia. 2002; 65(1):83-7. http://dx.doi.org/10.1590/S0004-27492002000100016.

Jorgensen B, Price P, Andersen KE, Gottrup F, Bech-Thomsen N, Scanlon E, Kirsner R, Rheinen H, Roed-Petersen J, Romanelli M, Jemec G, Leaper DJ, Neumann MH, Veraart J, Coerper S, Agerslev RH, Bendz SH, Larsen JR, Sibbald RG. The silver-releasing foam dressing, Contreet Foam, promotes faster healing of critically colonised venous leg ulcers: a randomised, controlled trial. International Wound Journal. 2005; 2(1):64-73. http://dx.doi.org/10.1111/j.17424801.2005.00084.x. PMid:16722854.

Marques C, Martins A, Conrado LA. The use of hyperbaric oxygen therapy and LED therapy in diabetic foot. In: Rechmann P, Fried D, Hennig T, editors. Proceedings of SPIE 5312, Lasers in Surgery: Advanced Characterization, Therapeutics, and Systems XIV; 2004 July 13; Bellingham, USA. Bellingham: SPIE; 2004 p. 47-53.

Minatel DG, Enwemeka CS, Franca SC, Frade MAC. Fototerapia (LEDs 660/890nm) no tratamento de ulceras de perna em pacientes diabéticos: Estudo de caso. Anais Brasileiros de Dermatologia. 2009; 84(3):279-83. http://dx.doi. org/10.1590/S0365-05962009000300011. PMid:19668943.

Mrue F. Neoformação tecidual induzida por biomembrana de látex natural com polilisina. Aplicabilidade na neoformação esofágica e da parede abdominal. Estudo experimental em cães [thesis]. Ribeirão Preto: Universidade de São Paulo; 2000. $112 \mathrm{p}$

Nteleki B, Houreld NN. The use of phototherapy in the treatment of diabetic ulcers. Journal of Endocrinology. Metabolism and Diabetes of South Africa. 2012; 17(3):12832. http://dx.doi.org/10.1080/22201009.2012.10872291.

Reis MC. Sistema indutor de neoformação tecidual para pé diabético com circuito emissor de luz de LEDs e utilização do látex natural [thesis]. Brasília: Universidade de Brasilia; 2013. 163 p

Robson MC, Steed DL, Franz MG. Wound healing: biologic features and approaches to maximize healing trajectories. Current Problems in Surgery. 2001; 38(2):72-140. http:// dx.doi.org/10.1067/msg.2001.111167. PMid:11452260. 
Rodrigues SS. Desenvolvimento de um sistema físico de controle de fluxo esofagiano para o tratamento da obesidade [thesis]. Brasília: Universidade de Brasília; 2008. 106 p.

Siqueira CPCM, de Oliveira TF, de Lima FM, Silva FP, Durante H, Dias IFL, Duarte JL, Kashimoto RK, Castro VAB. Efeitos biológicos da luz: aplicação de terapia de baixa potencia empregando LEDs (Light Emitting Diode) na cicatrização da ulcera venosa: relato de caso. Semina. Ciências Biológicas e da Saúde. 2009; 30(1):37-46.

Souza APC. Efeitos das radiações LED e LASER associadas ou nao no reparo de feridas cutâneas em dorso de ratos: estudo histológico [thesis]. Salvador: Universidade Federal da Bahia; 2008.142 p.

Wang W, Lin S, Xiao Y, Huang Y, Tan Y, Cai L, Li X. Acceleration of diabetic wound healing with chitosancrosslinked collagen sponge containing recombinant human acidic fibroblast growth factor in healing-impaired STZ diabetic rats. Life Sciences. 2008; 82(3-4):190-204. http:// dx.doi.org/10.1016/j.lfs.2007.11.009. PMid:18164317.

Wild S, Roglic G, Green A, Sicree R, King H. Global prevalence of diabetes: estimates for the year 2000 and projections for 2030. Diabetes Care. 2004; 27(5):1047-1053.

Yu W, Naim JO, Lanzafame RJ. Effects of photostimulation on wound healing in diabetic mice. Lasers in Surgery and Medicine. 1997; 20(1):56-63. http://dx.doi.org/10.1002/ (SICI)1096-9101(1997)20:1<56::AID-LSM9>3.0.CO;2-Y. PMid:9041509.

Zimmermann M, Raiser AG, Barbosa ALT, Novosad D, Steffen RPB, Lukarsewsk R, Silva MS, Lindinger R, Pastore F Jr. Teste de Biocompatibilidade e resistência de membranas de látex em cães. Ciência Rural. 2007; 37(6):1719-23. http:// dx.doi.org/10.1590/S0103-84782007000600033.

\section{Authors}

Gustavo Adolfo Marcelino de Almeida Nunes ${ }^{1 *}$, Maria do Carmo dos Reis ${ }^{1,2}$, Mário Fabrício Fleury Rosa ${ }^{3}$, Luciana Roberta Tenório Peixoto ${ }^{4,5}$, Adson Ferreira da Rocha ${ }^{1,4}$, Suélia de Siqueira Rodrigues Fleury Rosa ${ }^{1,2}$

${ }^{1}$ Graduate Program in Biomedical Engineering, Biomedical Engineering Laboratory - BioEngLab, Gama Faculty, Universidade de Brasilia - UNB, Área Especial de Indústria, Projeção A, Gama - Setor Leste, CEP 72444-240, Brasilia, DF, Brazil.

${ }^{2}$ Graduate Program on Electronic Systems and Automation Engineering - PGEA, Department of Electrical Engineering, Universidade de Brasilia - UnB, Brasilia, DF, Brazil.

${ }^{3}$ Graduate Program in Health Sciences and Technologies, Universidade de Brasilia - UnB, Brasilia, DF, Brazil.

${ }^{4}$ Graduate Program in Medical Sciences, School of Medicine, Universidade de Brasilia - UnB, Brasilia, DF, Brazil.

${ }^{5}$ Laboratory of Robotics and Automation - LARA, Department of Electrical Engineering, Universidade de Brasilia UnB, Brasilia, DF, Brazil. 